OPEN ACCESS

Edited by:

Eric Yiou,

Université Paris-Sud, France

Reviewed by:

Sjoerd Bruijn,

VU University Amsterdam

Netherlands

Didier Pradon,

INSERM U1179 Handicap

Neuromusculaire: Physiopathologie,

Biothérapie et Pharmacologie

Appliquées (END-ICAP), France

${ }^{*}$ Correspondence:

Nils Eckardt

nils.eckardt@uol.de

Received: 28 August 2018 Accepted: 04 February 2019

Published: 27 February 2019

Citation:

Eckardt N and Rosenblatt N (2019) Instability Resistance Training Decreases Motor Noise During Challenging Walking Tasks in Older Adults: A 10-Week Double-Blinded RCT. Front. Aging Neurosci. 11:32. doi: 10.3389/fnagi.2019.00032

\section{Instability Resistance Training Decreases Motor Noise During Challenging Walking Tasks in Older Adults: A 10-Week Double-Blinded RCT}

\author{
Nils Eckardt ${ }^{1,2 *}$ and Noah J. Rosenblatt ${ }^{3}$ \\ 'Department of Training and Movement Science, Institute for Sport and Sports Science, University of Kassel, Kassel, \\ Germany, ${ }^{2}$ Department of Sport and Movement Science, Institute of Sport Science, Carl von Ossietzky University \\ of Oldenburg, Oldenburg, Germany, ${ }^{3}$ Dr. William M. Scholl College of Podiatric Medicine's Center for Lower Extremity \\ Ambulatory Research (CLEAR), Rosalind Franklin University of Medicine and Science, North Chicago, IL, United States
}

Locomotor stability is challenged by internal perturbations, e.g., motor noise, and external perturbations, e.g., changes in surface compliance. One means to compensate for such perturbations is to employ motor synergies, defined here as co-variation among a set of elements that acts to stabilize, or provide similar trial-to-trial (or step-to-step) output, even in the presence of small variations in initial conditions. Whereas evidence exists that synergies related to the upper extremities can be trained, the extent to which lower limb synergies, such as those which may be needed to successfully locomote in complex environments, remains unknown. The purpose of this study was to evaluate if resistance training $(R T)$ in unstable environments could promote coordination patterns associated with stronger synergies during gait. Sixty-eight participants between the age of 65 and 80 were randomly assigned to one of three different RT modalities: stable whole-limb machine-based RT (S-MRT), instability free-weight RT (I-FRT), and stable machine-based adductor/abductor RT (S-MRT $\left.T_{H I P}\right)$. Before and after RT, participants walked across an even lab floor and a more challenging uneven surface with and without holding a weighted bag. The uncontrolled manifold control analysis (UCM) was used to calculate the synergy index (i.e., strength of the kinematic synergy) related to stabilization of our performance variable, the mediolateral trajectory of the swing foot, under each condition. Regardless of RT group, there was no effect of RT on the synergy index when walking across the even lab floor. However, the synergy index during the two uneven surface conditions was stronger after I-FRT but was not affected by the other RT modalities. The stronger synergy index for the I-FRT group was due to improved coordination as quantified by an overall increase in variability in elemental variable space but a decrease in the variability that negatively affects performance. The unstable environment offered by I-FRT allows for exploration of motor solutions in a manner that 
appears to transfer to challenging locomotor tasks. Introducing tasks that promote, rather than limit, exploration of motor solutions seems to be a valuable exercise modality to strengthen kinematic synergies that cannot be achieved with traditional strengthening paradigms (e.g., S-MRT).

Clinical Trial Registration: www.ClinicalTrials.gov, identifier NCT03017365.

Keywords: irregular surface, unstable resistance training, uncontrolled manifold, motor redundancy, elderly, gait, perturbation

\section{INTRODUCTION}

Falls are a leading cause of injuries and mortality in older adults and the risk of falling increases with age (Rubenstein, 2006). Many falls in community-dwelling older adults occur during locomotion, particularly when postural stability is challenged by perturbations like slips and trips (Berg et al., 1997). Locomotor stability is generally realized through accurate positioning of the swing-foot relative to the center of mass (CoM) (Bruijn and van Dieën, 2018). In the frontal plane this requires active control by the central nervous system (Kuo, 2002; Bruijn and van Dieën, 2018) realized through activation of the swing limb hip musculature in response to states of the stance limb (Bruijn and van Dieën, 2018). However, increased neuromotor noise and associated motor variability (Kang and Dingwell, 2009) may negatively affects control of mediolateral (ML) foot placement and increases variability in ML placement of the foot (Bruijn and van Dieën, 2018), which may increase fall risk (Brach et al., 2005). Nonetheless, if an individual can compensate for increased variability, by channeling it into a subspace that does not affect performance, then the high variability would not be hazardous. The uncontrolled manifold (UCM) analysis provides a means to quantify the extent to which motor variability may or may not "be hazardous" (Latash et al., 2007).

The UCM analysis quantifies the extent to which all available degrees of freedom (DoF) that contribute to a task-relevant performance variable co-vary so as to stabilize (limit trial-totrial variation in) that performance variable (Scholz and Schöner, 1999; Latash et al., 2007). The analysis decomposes variability in a set of elemental variables into two components: "good" variance that has no effect on the performance variable and "bad" variance that results into deviations of the performance variable. A positive synergy index, which quantifies the relative amount of "good" variance compared to "bad" variance, implies that the performance variable is stabilized by a synergy (Scholz and Schöner, 1999; Latash et al., 2007). Such stabilization allows secondary tasks that rely on the same set of elemental variables to be performed without affecting the primary task. It is generally thought that the effects of aging on motor coordination manifest as low amounts of "good variance" (Kapur et al., 2010). However, in response to challenging locomotor conditions such as uneven surface walking, healthy community-dwelling older adults are able to counteract perturbation-related increases in "bad" variability by channeling elemental variability into "good" variability (Eckardt and Rosenblatt, 2018). Similar findings have been reported for upper extremity tasks (Kapur et al., 2010).
Thus, the aging human CNS possess the ability to harness motor flexibility, i.e., to increase the synergy index by increasing "good" variance through exploration of motor solution space. Given its' importance, there is a need to understand whether this ability is trainable and if so, what exercises are optimal to train this ability.

With regard to the upper extremity, it has been demonstrated that non-repetitive tasks performed under conditions of manipulated stability can help promote large amounts of "good" variance (Shim et al., 2008; Wu and Latash, 2014). Similarly it has been suggested that exercise interventions which introduce tasks that promote, rather than limit, exploration of motor solutions may be particularly appropriate for promoting motor flexibility and the coordination patterns utilized to ambulate in complex environments (Rosenblatt et al., 2014). In turn, such exercises may help to reduce risk of falling and their introduction into fall prevention interventions would represents a considerable departure from traditional exercises, such as resistance training (RT) that targets muscle strength and power to achieve this goal (Benichou and Lord, 2016). Indeed, machine-based resistance training (S-MRT) does not seem suited to promote exploration of motor solutions due to restricted movements during exercise execution; a combination of balance and resistance training, i.e., "instability free-weight resistance training" (I-FRT), may be better suited to do this.

Instability free-weight RT is an exercise modality which involves tasks that specifically promote exploration of motor solutions by having participants engage in RT training while standing on destabilizing surfaces. The inherent instability during execution of the I-FRT results in greater overall muscle activation of the lower limbs due to the constant need for postural readjustment (Lawrence and Carlson, 2015). Indeed, the greater demands of I-FRT may explain why in our recent 10 -week RCT I-FRT elicited similar increases in balance, power, and strength in older adults compared to S-MRT despite using half the training load (Eckardt, 2016). We hypothesized that inter-and intramuscular coordination may be the driving reason for increases in the respective outcomes. Nonetheless, strength, power, and balance are measures of performance that do not directly address changes in coordination such as those quantified by synergies within the UCM analysis. There is evidence, albeit limited, that RT can improve synergies; one study has evaluated the effects of finger RT on finger synergies, independence, force control and adaptations in multi-finger coordination (Shim et al., 2008). If RT does impact synergies, then RT focusing on the hip could be particularly beneficial with regards to improving kinematic synergies related to the mediolateral trajectory of the 
swing-foot during gait. Indeed, swing limb hip abductors activity is critical in modulating foot placement and is predicted by the relationship between the CoM and the stance limb (Rankin et al., 2014; Roden-Reynolds et al., 2015). On the other hand, strengthening may not significantly affect swing limb mechanics, which in part contribute to kinematic synergies related to foot placement. For example, increasing strength by $26 \%$ (i.e., control condition relative to a weaker nerve block condition) does not affect swing limb kinematics (Pohl et al., 2015). In fact, it is entirely possible that weaker older adults employ stronger synergies to compensate for weakness, as has been argued to occur during sit-to-stand tasks (Greve et al., 2013) such that hip strengthening could lead to a reduction in synergies. Thus, the extent to which RT, and particularly hip-specific RT, can impact motor coordination during locomotion remains unclear.

The purpose of the current study was to quantify how different RT modalities affect kinematic synergies related to the mediolateral trajectory of the swing-foot during normal and perturbed gait (walking across an uneven surface with and without additional asymmetric loading that promote additional imbalance). In addition to evaluating the effect of I-FRT and standard S-MRT on kinematic synergies, we also evaluated a highly specific adductor/abductor resistance training $\left(\mathrm{S}-\mathrm{MRT}_{\mathrm{HIP}}\right)$ to better understand the extent to which hip strength affects kinematic synergies related to foot placement. We hypothesized first that kinematic synergies (i.e., synergy index) would stay invariant across groups from pre- to post testing during normal walking, given that normal walking is a habitual task. Second, we hypothesized that only the I-FRT group would increase the kinematic synergy index during perturbed gait (in absence of prior literature, we assumed the null for

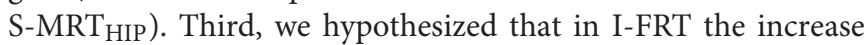
of the kinematic synergy index would result from an increase in "good" variance and a decrease in "bad" variance due to improved co-variation of lower-extremities based a previous study (Wu and Latash, 2014).

\section{METHODS}

\section{Study Design}

We conducted a registered three-arm, double-blinded RCT (ClinicalTrials.gov: NCT03017365 on 01/04/2017) examining the effects of three (RT) protocols on kinematic synergies and strength, power, and balance in older adults. The assessors were blinded to the participants' assignments. Participants were naïve to the study hypothesis. The trial was approved by the local ethics committee of the University of Kassel (E052016058) and was complied with the relevant ethical standards of the latest Declaration of Helsinki (WMA, October 2013). All participants provided written informed consent prior to enrollment.

\section{Participants}

In total 82 participants between the age of 65 and 80 were recruited via public advertisement. The only inclusion criteria were the ability to walk independently without any gait aid. Participants were excluded based on pathological ratings of the
Clock Drawing Test (CDT) (Nair et al., 2010), the Mini-MentalState-Examination (MMSE, $<24$ points) (Lopez et al., 2005), the Falls Efficacy Scale - International (FES-I, $>24$ points) (Dias et al., 2006), the Geriatric Depression Scale (GDS, >9 points) (Parmelee and Katz, 1990), the Freiburg Questionnaire of Physical Activity (FQoPA, <1 h) (Frey and Berg, 2002) and the Frontal Assessment Battery (FAB-D, <13 points) (Benke et al., 2013). Ultimately, 68 participants successfully completed the trial. Figure 1 shows the CONSORT flow diagram and the number of participants in the treatment arms at each stage of the trial. Subject' demographics and baseline descriptors of the who completed the 10-week trial are presented in Table 1.

\section{Randomization}

Participants were stratified (1:1:1) into one of three groups according to age and sex. An uninvolved researcher then randomly assigned the groups to one of three training modalities: Machine-based stable resistance training (S-MRT), freeweight instability resistance training (I-FRT), or machinebased adductor/abductor resistance training $\left(\mathrm{S}-\mathrm{MRT}_{\mathrm{HIP}}\right)$. The randomization sequence was generated using www.randomizer. org and was concealed until groups were stratified.

\section{Assessment}

Data was collected in the biomechanics laboratory of the University of Kassel, Germany.

\section{Kinematic Data Collection, Processing and Analysis}

Twenty-six $12.5 \mathrm{~mm}$ reflective markers were attached bilaterally to the legs with double-sided adhesive tape at prominent bony landmarks according the IOR lower-body marker-set (Leardini et al., 2007). A six-camera motion capture system (Oqus 3+, Qualisys AB, Gothenburg, Sweden) operating at $120 \mathrm{~Hz}$ was used to record marker trajectories. Participants then walked for $1 \mathrm{~min}$ back and forth through a capture volume of $5 \mathrm{~m}$ at a self-selected walking speed. The capture volume was preceded/proceeded by $\sim 2 \mathrm{~m}$ which allowed the participant to accelerate/decelerate before entering/exiting the capture volume. Participants completed three conditions: the even surface (ES) (control) condition where they walked across the lab floor; the uneven surface (US) condition where foam panels (terrasensa ${ }^{\circledR}$ classic; Huebner, Kassel, Germany; see Figure 2) were placed on the floor to create an uneven surface; and the "imbalanced shopping bag" (ISB) condition where they walked across the US carrying a simulated shopping bag - i.e., a tube, lanced with a chain with ends weights attached (5\% of the body

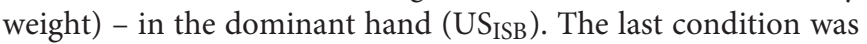
intended to present an additional challenge to balance above the US condition alone. All data were processed using Visual3D (C-Motion, Germantown, MD, United States). Raw kinematic marker trajectories were interpolated and smoothed with a fourth-order zero-lag Butterworth low-pass filter with a cut-off frequency of $6 \mathrm{~Hz}$. The UCM-analysis was then performed on the processed data using a custom written R-code ( $\mathrm{R}$ Foundation for Statistical Computing, Vienna, Austria). The custom code is available upon request. 


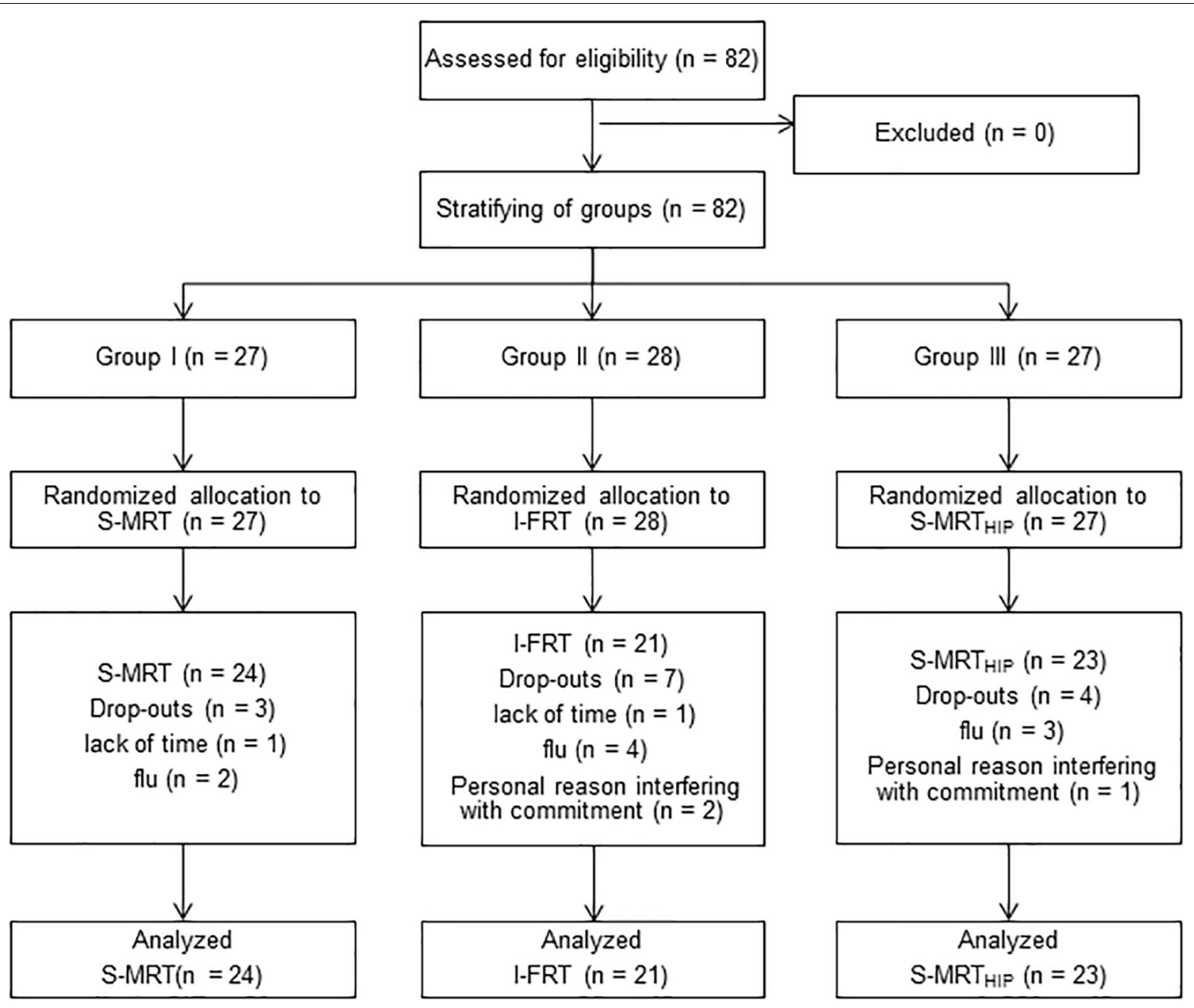

FIGURE 1 | CONSORT diagram with participant flow. S-MRT, stable machine-based resistance training; I-FRT, instability free-weight resistance training; S-MRT HIP, stable machine-based adductor/abductor resistance training.

\section{Primary Measures: Uncontrolled Manifold Analysis}

The UCM approach has been described in detail elsewhere (Scholz and Schöner, 1999; Latash et al., 2007) as has its application to stabilizing the swing limb trajectory during gait (Rosenblatt et al., 2015; Eckardt and Rosenblatt, 2018). Briefly, motion capture data was normalized to $0-100 \%$ corresponding to left toe off to heel strike. A geometric model was used to express the position of the swing limb at each percent of swing as a function of seven lower limb segment angles. For each step and at each percent of swing, the deviation between each angle and it's across-step average was calculated. A deviation vector was then projected onto a 6-DOF space that did not affect the swing limb position and a 1 DOF space that did, based on the Jacobian of the geometric model. The across-step average length of the projected vectors defined "good" and "bad" variance, respectively, at every percent of swing from which a synergy index was expressed. Consistent with prior studies (Krishnan et al., 2013; Rosenblatt et al., 2015; Eckardt and Rosenblatt, 2018), the variance components and synergy index were averaged across the swing phase for further analysis. The primary outcome from the analysis is the synergy index, which was z-transformed prior to statistical testing $\left(\Delta \mathrm{V}_{\mathrm{Z}}\right)$. The index was calculated as the difference between the "good" variance per DOF $\left(\mathrm{V}_{\mathrm{UCM}}\right)$ and "bad" variance per DOF $\left(\mathrm{V}_{\mathrm{ORT}}\right)$ relative to the total kinematic variance per all DOFs $\left(\mathrm{V}_{\text {TOT }}\right)$ such that changes in $\Delta \mathrm{V}_{\mathrm{Z}}$ can reflect multiple strategies (Wu and Latash, 2014). Therefore, in addition to $\Delta \mathrm{V}_{\mathrm{Z}}$, we also report $\mathrm{V}_{\mathrm{UCM}}, \mathrm{V}_{\mathrm{ORT}}$, and $\mathrm{V}_{\mathrm{TOT}}$. $\mathrm{A}$ more detailed description of the UCM method can be found in Supplementary Material SII.

\section{Secondary Measures}

\section{Balance assessment}

We tested proactive balance using the timed-up-and-go test (TUG) (Podsiadlo and Richardson, 1991) and the multidirectional reach test (MDRT) (Newton, 2001). For the TUG, participants were asked to rise from a chair and walk three meters at their habitual walking speed, turn around a cone return to the chair and then sit down. Time was recorded to the 
TABLE 1 | Subject characteristics and descriptive values.

\begin{tabular}{|c|c|c|c|c|c|c|c|}
\hline \multirow[b]{2}{*}{ Characteristics } & \multicolumn{2}{|c|}{$\begin{array}{l}\text { S-MRT } \\
(n=24)\end{array}$} & \multicolumn{2}{|c|}{$\begin{array}{c}\text { I-FRT } \\
(n=21)\end{array}$} & \multicolumn{2}{|c|}{$\begin{array}{c}\text { S-MRT } \\
\quad(n=23)\end{array}$} & \multirow{2}{*}{$\begin{array}{c}\text { Baseline } \\
\text { difference } \\
p \text {-value }\end{array}$} \\
\hline & $M$ & $S D$ & $M$ & $S D$ & $M$ & $S D$ & \\
\hline Age (years) & 69.5 & 3.8 & 71.3 & 3.9 & 69.9 & 3.9 & 0.288 \\
\hline Body height (cm) & 169 & 7 & 171 & 9 & 169 & 9 & 0.820 \\
\hline Body mass (kg) & 73.8 & 12.4 & 76.9 & 15.7 & 76.6 & 13.6 & 0.691 \\
\hline $\operatorname{Sex}(f / m)$ & \multicolumn{2}{|c|}{$16 / 8$} & \multicolumn{2}{|c|}{$12 / 9$} & \multicolumn{2}{|c|}{$13 / 10$} & - \\
\hline Physical activity (h/w) & 11.9 & 8.6 & 9.4 & 9.2 & 12.2 & 7.2 & 0.215 \\
\hline MMSE & 27.8 & 1.8 & 27.9 & 1.6 & 28.0 & 1.6 & 0.914 \\
\hline CDT & \multicolumn{7}{|c|}{ all participants were classified as non-pathological } \\
\hline GDS & 1.1 & 1.6 & 0.9 & 1.0 & 1.0 & 1.4 & 0.957 \\
\hline FAB_D & 15.3 & 2.0 & 15.1 & 2.1 & 15.7 & 2.2 & 0.521 \\
\hline
\end{tabular}

S-MRT, stable machine based resistance training; I-FRT, instability free-weight resistance training; S-MRT HIP, stable machine based adductor/abductor resistance training; $M$, mean; $S D$, standard deviation; f, female; $m$, male; MMSE, Mini Mental State Examination; CDT, Clock Drawing Test; GDS, Geriatric Depression Scale; FAB_D, Frontal Assessment Battery, German Version.

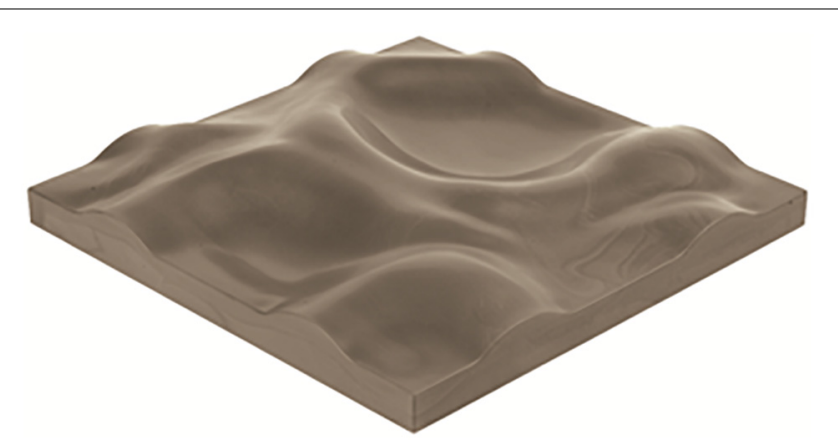

FIGURE 2 | Artificial uneven surface. The terrasensa ${ }^{\circledR}$ foam panels consist of polyurethane with the following material properties: shore durometer hardness scale A (DIN 53505) = $50 \pm 5$; impact resilience (DIN 53512) $R=50$.

nearest $0.01 \mathrm{~s}$ using a stopwatch that started on the command "ready-set-go" and stopped as soon as the participants sat down. The MDRT measures the maximal distance participants could reach forward, backward, left, and right while standing without taking a step. Maximal reach distance $(\mathrm{cm})$ was recorded. We added the left/right conditions and calculated the mean mediolateral distance for further analysis. Participants had one practice trial for every test. Two test trials were carried out and the mean was entered into statistical analysis.

\section{Strength and power assessment}

Maximal isometric leg extension strength was examined with the isometric mid-thigh pull test (IMTP) (McMaster et al., 2014). Data was measured with a force plate (Model 9281B, Kistler Instrument AG, Winterthur, Switzerland), operating at $1200 \mathrm{~Hz}$ and recorded with QTM (Qualisys AB, Gothenburg, Sweden). Participants stood upright in a squatting position on a solid, elevated metal platform, bridging over the force plate to avoid contact. Cable length was individualized to guarantee a constant knee angle of approximately $135^{\circ}$. Participants were then asked to pull upward on a handle connected to the force plate, starting initially with a moderate intensity and slowly increase the intensity to maximum exertion while keeping the upper body extended and upright. To ensure upright posture, an assessor put her hand on the participants' back while pulling. The IMTP shows high within- and between-session reliability (ICC $\geq 0.87$ ) (Moeskops et al., 2018).

Bilateral isometric strength of hip adduction and abduction, as well as the knee extensor, was measured with a handheld dynamometer (Lafayette Instrument Company, Lafayette, IN, United States) (Arnold et al., 2010). To measure hip adduction and abduction, participants were positioned sideways on a therapy bench. The hand-held dynamometer was placed above the malleolus of the lower (adduction) or upper leg (abduction) respectively, as previously described (Arnold et al., 2010). Participants were asked to adduct and abduct their respective leg. For knee extension strength, participants sat on the therapy bench and were asked to try to extend their leg. The assessor placed the hand-held dynamometer at the lower leg just proximal to the ankle. We recorded two maximum effort isometric contractions for 3-5 s with each muscle group. Interclass correlation coefficients (ICCs) are generally high for hand-held dynamometry (ICCs 0.95-0.99) (Arnold et al., 2010). For all isometric strength testing, we provided one practice trial and then averaged the next two trials. Measures were taken on both limbs and then averaged across limbs prior to statistical analysis. To limit the effects of fatigue we allowed recovery periods ( $>1 \mathrm{~min}$ ) between trials.

To assess lower extremity muscle power, we administered the Five Times Sit-to-Stand-Test (STS) (Tiedemann et al., 2008). Participants were instructed to stand up and sit down five times as quickly as possible, without using their arms. They were advised to fold their arms across the upper body. Time was measured by a stopwatch to the nearest $0.01 \mathrm{~s}$. After the countdown "ready-setgo," testing time was started and stopped when participants sat down for the fifth time.

\section{Questionnaires}

Global cognitive function was assessed using the MMSE, a screening tool for mild cognitive impairment (Lopez et al., 2005). The FAB-D consists of six neuropsychological tasks, evaluating cognitive and behavioral frontal lobe functions (Dubois et al., 2000). Physical activity was assessed using the FQPA (Frey and Berg, 2002). Concern about falling was evaluated using FES-I (Dias et al., 2006). The FES-I was the only questionnaire applied pre- and post-testing. All other tests were used for screening purposes and/or to describe the population.

\section{Exercise Intervention}

The exercise intervention took place between January and April. Training was supervised by two trained instructors providing a participant to instructor ratio of 5:1. All intervention groups trained for 10 weeks, twice per week on non-consecutive days for 60 min per day. We began with a 1-week introductory phase and three training blocks lasting 3 weeks each. Training intensity was progressively and individually increased by modulating load and sets for all groups and the level of instability for the I-FRT group (see Table 2). After week one, four, and seven the training 
TABLE 2 | Detailed intervention program for all groups and phases.

\begin{tabular}{|c|c|c|c|c|}
\hline & Intro-phase ( 1 week) & Block I (3 weeks) & Block II (3 weeks) & Block III (3 weeks) \\
\hline & $\begin{array}{l}\sim 2 \times 12 \text { reps (with low } \\
\text { weights, } 2-3 \text { min rest } \\
\text { between sets and } 5 \text { min } \\
\text { between exercises) }\end{array}$ & $\begin{array}{l}3 \times 15 \text { reps (50\% of the } 1-\mathrm{RM} \text {, } \\
2-3 \text { min rest between sets and } \\
5 \text { min between exercises) }\end{array}$ & $\begin{array}{l}3-4 \times 15 \text { reps (60\% of } \\
\text { the } 1-\mathrm{RM}, 2-3 \mathrm{~min} \text { rest } \\
\text { between sets and } 5 \mathrm{~min} \\
\text { between exercises) }\end{array}$ & $\begin{array}{l}4 \times 15 \text { reps ( } 60 \% \text { of the } 1-\mathrm{RM} \text {, } \\
2-3 \text { min rest between sets and } \\
5 \text { min between exercises) }\end{array}$ \\
\hline \multicolumn{5}{|l|}{ S-MRT } \\
\hline Cross-Trainer & $10 \mathrm{~min}$ & $10 \mathrm{~min}$ & $10 \mathrm{~min}$ & $10 \mathrm{~min}$ \\
\hline Smith-Machine & $150^{\circ}$ knee flex/ext angle & $120^{\circ}$ knee flex/ext angle & $100^{\circ}$ knee flex/ext angle & $100^{\circ}$ knee flex/ext angle \\
\hline Leg-Press & $90^{\circ}$ knee flex/ext angle & $90^{\circ}$ knee flex/ext angle & $90^{\circ}$ knee flex/ext angle & $90^{\circ} \mathrm{knee}$ flex/ext angle \\
\hline Core Exercise & Bridge exercise ( $2 \times 15$ reps) & Bridge exercise ( $3 \times 20$ reps) & Crunches $(4 \times 20$ reps $)$ & Air Bike Crunches ( $4 \times 20$ reps) \\
\hline $\begin{array}{l}\text { Walking with } \\
\text { dumbbells }\end{array}$ & 2 min without dumbbells & 3 min with $5 \%$ of bw & 4 min with $10 \%$ of bw & 5 min with $15 \%$ of bw \\
\hline \multicolumn{5}{|l|}{ I-FRT } \\
\hline Cross-Trainer & $10 \mathrm{~min}$ & $10 \mathrm{~min}$ & $10 \mathrm{~min}$ & $10 \mathrm{~min}$ \\
\hline Squats & $\begin{array}{l}150^{\circ} \text { knee flex/ext angle on } \\
\text { AIREX }{ }^{\oplus} \text { coordination rocker } \\
\text { board round }\end{array}$ & $\begin{array}{l}120^{\circ} \text { knee flex/ext angle on } \\
\text { Thera-Band }{ }^{\oplus} \text { balance pads placed } \\
\text { on AIREX }{ }^{\ominus} \text { coordination rocker } \\
\text { board angled }\end{array}$ & $\begin{array}{l}100^{\circ} \text { knee flex/ext angle on } \\
\text { AIREX }{ }^{\circledR} \text { balance pad placed } \\
\text { on AIREX }{ }^{\circledR} \text { coordination } \\
\text { rocker board angled }\end{array}$ & $\begin{array}{l}100^{\circ} \text { knee flex/ext angle on } \\
\text { BOSU }{ }^{\circledR} \text { ball or Variosensa } \\
\text { board }\end{array}$ \\
\hline Front lunges & $\begin{array}{l}\text { Thera-Band }{ }^{\circledR} \text { Balance Pads } \\
\text { (front foot) }\end{array}$ & $\begin{array}{l}\text { AIREX }{ }^{\circledR} \text { coordination rocker board } \\
\text { round (front foot) and Thera-Band }{ }^{\circledR} \\
\text { Balance Pads (rear foot) }\end{array}$ & $\begin{array}{l}\text { AIREX }{ }^{\circledR} \text { balance pad (front } \\
\text { foot) and Thera-Band }{ }^{\circledR} \\
\text { Balance Pads (rear foot) }\end{array}$ & $\begin{array}{l}\text { AIREX }{ }^{\circledR} \text { balance pad (front } \\
\text { foot) and AIREX }{ }^{\circledR} \text { balance } \\
\text { spinner soft (rear foot) }\end{array}$ \\
\hline $\begin{array}{l}\text { Core Exercise } \\
\text { (Bridge Exercise) }\end{array}$ & $\begin{array}{l}\text { No additional device }(2 \times 15 \\
\text { reps) }\end{array}$ & $\begin{array}{l}\text { TOGU }{ }^{\circledR} \text { DYNAIR }{ }^{\circledR} \text { (under feet) } \\
(3 \times 20 \text { reps })\end{array}$ & $\begin{array}{l}\text { TOGU }{ }^{\circledR} \text { DYNAIR }{ }^{\circledR} \text { (under } \\
\text { shoulder) and BOSU (under } \\
\text { feet) }(4 \times 20 \text { reps) }\end{array}$ & $\begin{array}{l}\text { Swiss ball (under feet) }(4 \times 20 \\
\text { reps) }\end{array}$ \\
\hline $\begin{array}{l}\text { Walking with } \\
\text { dumbbells }\end{array}$ & $\begin{array}{l}2 \text { min without dumbbells on } \\
\text { terrasensa }^{\circledR} \text { flats }\end{array}$ & $\begin{array}{l}3 \text { min with } 5 \% \text { of bw on } \\
\text { terrasensa }^{\circledR} \text { flats }\end{array}$ & $\begin{array}{l}4 \text { min with } 10 \% \text { of bw on } \\
\text { terrasensa }{ }^{\circledR} \text { classics }\end{array}$ & $\begin{array}{l}5 \text { min with } 15 \% \text { of bw on } \\
\text { terrasensa }\end{array}$ \\
\hline \multicolumn{5}{|l|}{ S-MRT } \\
\hline Cross-Trainer & $10 \mathrm{~min}$ & $10 \mathrm{~min}$ & $10 \mathrm{~min}$ & $10 \mathrm{~min}$ \\
\hline Adductor & Habituation & Full ROM & Full ROM & Full ROM \\
\hline Abductor & Habituation & Full ROM & Full ROM & Full ROM \\
\hline $\begin{array}{l}\text { Adductor } \\
\text { Thera-Band }\end{array}$ & Habituation & Full ROM & Full ROM & Full ROM \\
\hline $\begin{array}{l}\text { Abductor } \\
\text { Thera-Band }{ }^{\ominus}\end{array}$ & Habituation & Full ROM & Full ROM & Full ROM \\
\hline Core Exercise & $\begin{array}{l}\text { Side plank on knees }(2 \times 15 \\
\text { reps) }\end{array}$ & Side crunches $(3 \times 20$ reps $)$ & $\begin{array}{l}\text { Standing oblique crunch } \\
(4 \times 20 \text { reps })\end{array}$ & $\begin{array}{l}\text { Russian sitting twist with } \\
\text { dumbbell } 5 \% \text { bw, }(4 \times 20 \text { reps })\end{array}$ \\
\hline $\begin{array}{l}\text { treadmill walking } \\
\text { on robowalk }{ }^{\circledR}\end{array}$ & 2 min habituation & $\begin{array}{l}3 \text { min with } \mathrm{ML} \text { pull above knee joint } \\
\text { with } 5 \% \text { of bw }\end{array}$ & $\begin{array}{l}4 \text { min with ML pull at ankles } \\
\text { with } 5 \% \text { of bw }\end{array}$ & $\begin{array}{l}5 \text { min with ML pull above knee } \\
\text { joint and at ankles with } 5 \% \text { of } \\
\text { bw, respectively }\end{array}$ \\
\hline
\end{tabular}

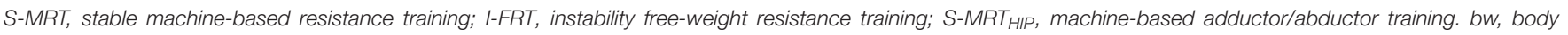
weight; 1-RM, one repetition maximum; BOSU, BOth Sides Utilized; ROM, Range of Motion; ML, mediolateral.

load (weight) was increased following one repetition maximum (1-RM) testing using the prediction equation provided by Epley (Reynolds et al., 2006) for each major exercise. The 1-RM was performed under stable conditions for every group.

\section{S-MRT}

The main exercises of this group were squats at the Smith machine, placing the barbell at the hip instead of putting it on the participant's shoulders, and the leg-press. Secondary exercise were core exercises and walking with weights across an even surface.

\section{I-FRT}

This group also performed squats, but instead of using the Smith machine, they exercised using instability devices (i.e., foam pads and BoSU balls) and dumbbells. The second main exercise was the front lunge on instability devices. Secondary exercises were core routines, incorporating instability devices, and walking across an uneven surface (terrasensa ${ }^{\circledR}$ classic; Huebner, Kassel, Germany) carrying dumbbells.

\section{S-MRT ${ }_{\text {HIP }}$}

The main exercises for this group were the thigh/hip adductorand abductor resistance machine. As secondary exercises, participants performed additional adduction and abduction exercises using elastic rubber straps. The resistance of the rubber straps was incrementally increased every block (changed by one color). Furthermore, lateral core exercises were introduced. In addition, this group walked across a special motorized treadmill (robowalk ${ }^{\circledR}, \mathrm{h} / \mathrm{p} / \mathrm{cosmos}$, Nußdorf, Germany), which applied a lateral pull via elastic straps at the ankle and/or knee while walking. 
Detailed description of the training programs and changes in intensities and degrees of instabilities can be found in Table 2 .

\section{Training Intensity}

Training intensity was quantified as the combined load (weight) for the two main exercises during the last training phase as determined from the participants' training sheets.

\section{Data Analysis}

An a priori sample size calculations with $\mathrm{G}^{*}$ Power 3.1.9.2 showed that to detect an expected effect of Cohen's $d=0.3$ (Shim et al., 2008; pilot data) at $\alpha=0.05$ with $1-\beta=0.90$ using a repeated measures with a within-between and interaction design, a total sample size of at least $N=15$ per group was required. Normality of the data was checked by visual inspection and tested with the Kolmogorov-Smirnov test for each dependent variable per group, prior to the main analysis. Given that ANOVAs are quite robust against violations of distribution (Schmider et al., 2010), we would only employ non-parametrical alternatives in the event that a variable was non-normal for at least two groups. Baseline differences were tested between groups with a one-way ANOVA. Given that gait speed affects gait kinematics, we compared gait speed between pre- and post-testing for all three conditions with dependent two-sided $t$-tests. The effect of treatment was analyzed separately for each of the primary and secondary outcomes using 2 (time: pre-test, post-test) $\times 3$ (group:

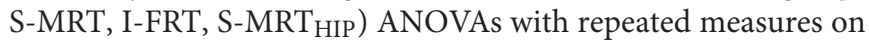
time and between subject factor being group. In the case of a significant interaction $(p \leq 0.05)$, post hoc tests (dependent twosided $t$-tests) were used to detect significant pre-post differences within each group. In addition, we investigated differences in the training load between groups using pre-planned independent two-sided $t$-tests. Ryan-Holm-Bonferroni corrected $p$-values for all $t$-tests are reported. Further, we employed Bayesian $t$-tests and calculated Bayes Factors (BF) to extend explanatory power of the inference $t$-tests results. We assume a default Cauchy prior width of 0.707. Table 3 summarizes the common interpretation of BF (Wetzels et al., 2011). To provide additional information, we also calculated the effect size as Cohen's $d$ for ANOVAs. Exploratory

TABLE 3 | Evidence categories for Bayes factor.

\begin{tabular}{ll}
\hline Bayes factor & \multicolumn{1}{c}{ Interpretation } \\
\hline$>100$ & Decisive evidence for $\mathrm{H}_{\mathrm{A}}$ \\
$30-100$ & Very strong evidence for $\mathrm{H}_{\mathrm{A}}$ \\
$10-30$ & Strong evidence for $\mathrm{H}_{\mathrm{A}}$ \\
$3-10$ & Substantial evidence for $\mathrm{H}_{\mathrm{A}}$ \\
$1-3$ & Anecdotal evidence for $\mathrm{H}_{\mathrm{A}}$ \\
1 & No evidence \\
$1 / 3-1$ & Anecdotal evidence for $\mathrm{H}_{0}$ \\
$1 / 10-1 / 3$ & Substantial evidence for $\mathrm{H}_{0}$ \\
$1 / 30-1 / 10$ & Strong evidence for $\mathrm{H}_{0}$ \\
$1 / 100-1 / 30$ & Very strong evidence for $\mathrm{H}_{0}$ \\
$<1 / 100$ & Decisive evidence for $\mathrm{H}_{0}$ \\
\hline
\end{tabular}

Adapted from Jeffreys (1961), cited in Wetzels et al. (2011). HO, Null-Hypothesis; HA, Alternative Hypothesis.
Software for Confidence Intervals was used to calculate Cohen's $d_{\text {unb }}$ (an unbiased estimate of the population effect size $\delta$ ), associated 95\% confidence intervals and the $t$-tests (Cumming, 2012). Following Cohen (Cohen, 1988), $d$-values $\leq 0.49$ indicate small effects, $0.50 \leq d \leq 0.79$ indicate medium effects, and $d \geq 0.80$ indicate large effects. Alpha level was set at $5 \%$. Bayesian $t$-tests were computed using JASP (Version 0.9.0.1). For all other tests we used IBM SPSS version 23.

\section{RESULTS}

The individual results are deposited as complete dataset in the Supplementary Material SI. The machine-based stable resistance training (S-MRT) group had an average attendance of $94 \%$, $95 \%$ for the free-weight instability resistance training (I-FRT) group, and $95 \%$ for the machine-based stable adductor/abductor resistance training ( $\left.\mathrm{S}-\mathrm{MRT}_{\mathrm{HIP}}\right)$ group. Gait speed increased from pre- to post-testing for conditions (Figure 3): ES $[t(66)=3.74$, $p<0.001, d_{\mathrm{unb}}=0.45 ; 95 \%$-CI $\left.(0.21,0.71) ; \mathrm{BF}_{10}=61.67\right]$, US $\left[t(66)=3.89, p=0.001, d_{\text {unb }}=0.41 ; 95 \%\right.$-CI $(0.16,0.67)$; $\left.\mathrm{BF}_{10}=21.84\right]$, and $\mathrm{US}_{\mathrm{ISB}}\left[t(66)=2.31, p=0.024, d_{\mathrm{unb}}=0.29\right.$; $95 \%$-CI $\left.(0.04,0.53) ; \mathrm{BF}_{10}=1.61\right]$. Based on our a priori criteria for non-parametric testing, we were able to use parametric test for all variables. All outcomes are summarized in Figures 4, 5.

\section{Primary Measures: Uncontrolled Manifold \\ Kinematic Synergy Index}

Regardless of group, $\Delta \mathrm{V}_{\mathrm{Z}}$ during the $\mathrm{ES}$ condition was not affected by RT (S-MRT: $-4 \%$ change; I-FRT: $2 \%$ change; S-MRT HIP $_{2} \%$ change). However, there was a time $x$ group interaction for both challenging walking conditions (Table 4). In particular, $\Delta \mathrm{V}_{Z}$ for I-FRT increased by $16 \%$ during US and $20 \%$ during US $_{\text {ISB }}$ whereas there was no significant change in the kinematic synergy during either condition for both S-MRT and S-MRT $\mathrm{HIP}_{\text {(Table 5). }}$

\section{VuCM}

Consistent with the fact that $\Delta \mathrm{V}_{\mathrm{Z}}$ during ES was not affected by any form of RT, we found no significant effect of time on "good" variance during the ES condition. In contrast, a main effect of time was observed for both unstable walking conditions. During the US condition we observed increases of 21\% (S-MRT), $28 \%$ (I-FRT), and 50\% (S-MRT $\left.\mathrm{MIP}_{\mathrm{H}}\right)$ for $\mathrm{V}_{\mathrm{UCM}}$, with similar effects across groups; i.e., no significant interaction was present. Similar results were seen for the $\mathrm{US}_{\mathrm{ISB}}$ condition; $\mathrm{V}_{\mathrm{UCM}}$ for this condition increased by $19 \%$ following S-MRT, by $28 \%$ following

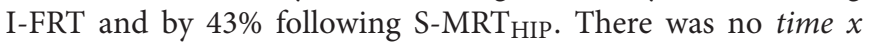
group interaction (Table 4).

\section{VORT}

Regardless of group there was no significant effect of time on $V_{\text {ORT }}$ during the ES condition. However, there was a significant time $x$ group interaction for both of the challenging conditions (Table 4). "Bad" variance decreased by $25 \%$ in the US condition following I-FRT and decreased by $24 \%$ in the US ISB condition. In 


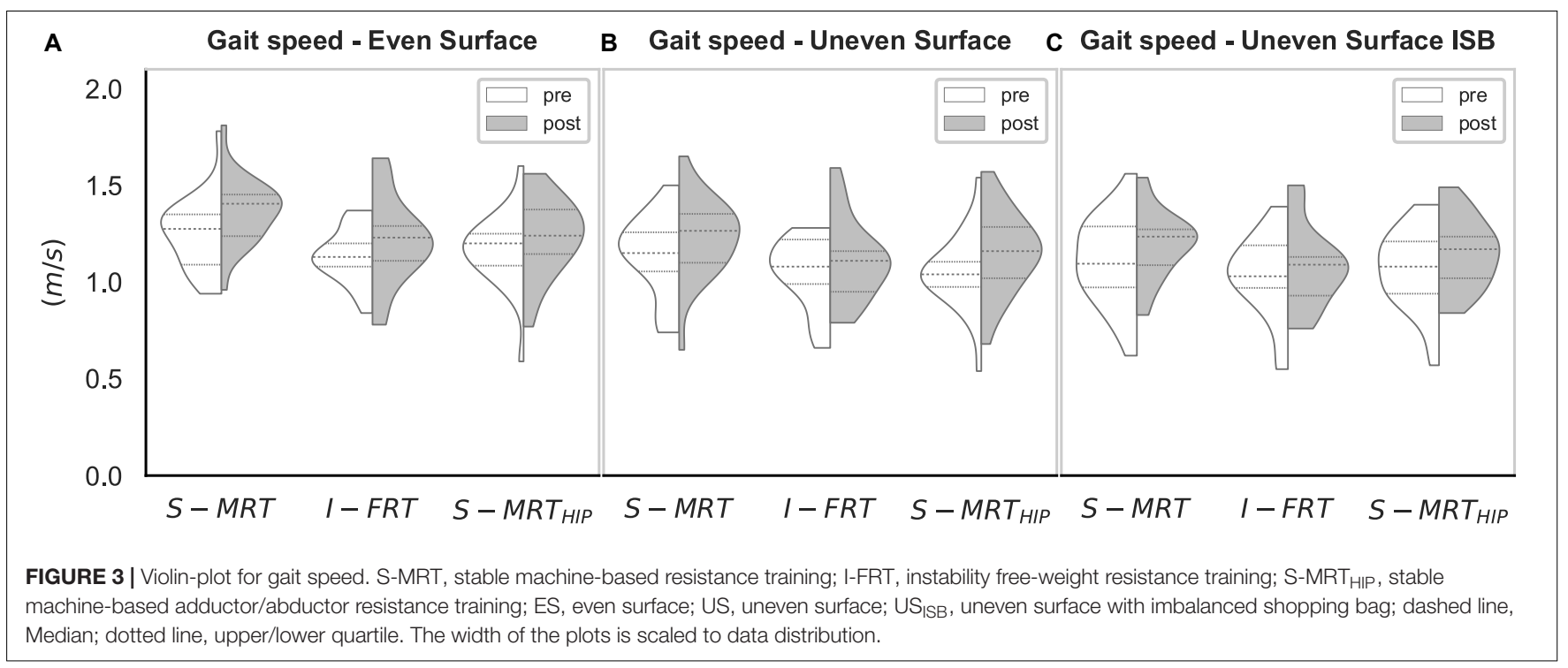

contrast to the I-FRT group, the other two groups significantly increased $\mathrm{V}_{\mathrm{ORT}}$ by more than $35 \%$ during the US condition following training. Similar increases were found for these groups

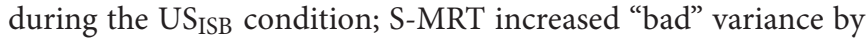
$35 \%$ and $\mathrm{S}-\mathrm{MRT}_{\mathrm{HIP}}$ by $41 \%$ (Table 5).

\section{$\mathrm{V}_{\text {TOT }}$}

Like $\mathrm{V}_{\mathrm{UCM}}$ and $\mathrm{V}_{\mathrm{ORT}}$, the total variance while walking across the even surface did not significantly change as a result of RT. However, there was a significant main effect of time on total variance during the two challenging conditions, with an average increase of $36 \%$ regardless of group; there was no significant time $x$ group interaction for either challenging condition (Table 4).

\section{Secondary Measures \\ Balance Assessment}

All groups reduced their TUG times by an average of $2 \%$. However, there was no significant effect of time on TUG (Table 4).

The effects of RT on proactive balance, measured by the MDRT were consistent across groups; regardless of group, participants improved their forward reaching skills by an average of $8 \%$ whereas backward leaning was not significantly improved with RT. There was a significant time $x$ group interaction for mediolateral proactive balance; with the S-MRT and I-FRT groups increasing side reaching by 4 and 14\%, respectively,

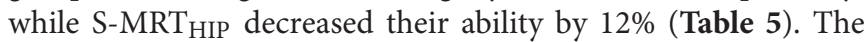
post hoc tests revealed that the change for S-MRT and S-MRT $\mathrm{HIP}_{\mathrm{P}}$ was not significant whereas the effects were significant for I-FRT (Table 5).

\section{Strength and Power Assessment}

Regardless of group, lower extremity muscle power, measured using the Five Times Sit-to-Stand task increased by $10 \%$ in all groups. There was no significant time $x$ group interaction (Table 4).
On average there was a $19 \%$ increase in isometric leg extension strength, but the effects varied by RT group; there was a significant time $x$ group interaction. The post hoc tests revealed a significant improvement for S-MRT and I-FRT, and no significant effect observed for S-MRT HIP $_{\text {(Table 5). }}$

There was no effect of time on hip adduction and abduction strength. However, isometric knee extension strength did increase by $14 \%$ with time. Nonetheless, changes across groups were similar for all strength variables, thus we found no interaction effect time $x$ group (Table 4).

\section{Training Intensity}

We found meaningful differences between groups, demonstrating that I-FRT exercised with considerably lower loads than the other groups. On average, I-FRT exercised on both main exercises with $\sim 150 \mathrm{~kg}$ less than S-MRT and with $\sim 56 \mathrm{~kg}$ less than S-MRT $T_{\text {HIP. See Figure } 6 .}$

\section{Questionnaire}

Fear of falling, measured with the FES-I, was significantly reduced over time by $3-7 \%$ but the effects were similar across groups. M-SRT reduced the FES-I score from $19.3 \pm 2.6$ to $18.0 \pm 2.3$, I-FRT from $20.0 \pm 3.7$ to $18.4 \pm 2.8$, and S-MRT HIP $_{\text {changed the }}$ score from $18.9 \pm 3.2$ to $18.3 \pm 2.4$.

\section{DISCUSSION}

The purpose of this study was to quantify the effect of different RT modalities on kinematic synergies (derived using UCM analysis) related to the ML trajectory of the swing-foot during normal and perturbed gait (walking across an uneven surface with and without additional weight/imbalance). Our first hypothesis, that the kinematic synergy for the ES condition would remain invariant for all groups after the intervention was supported. Our second hypothesis that the kinematic synergy during both unstable conditions would increase after training for the F-IRT 


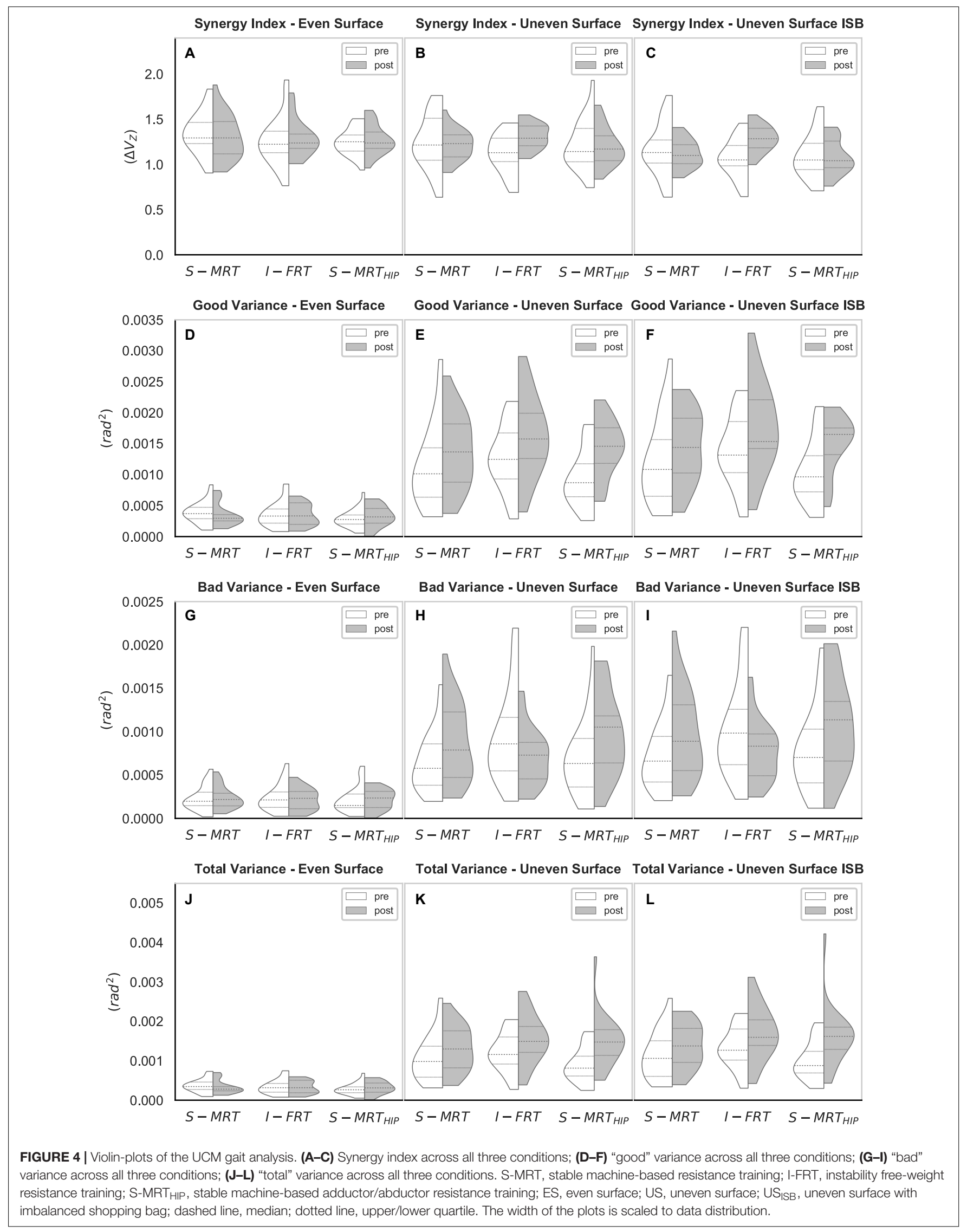




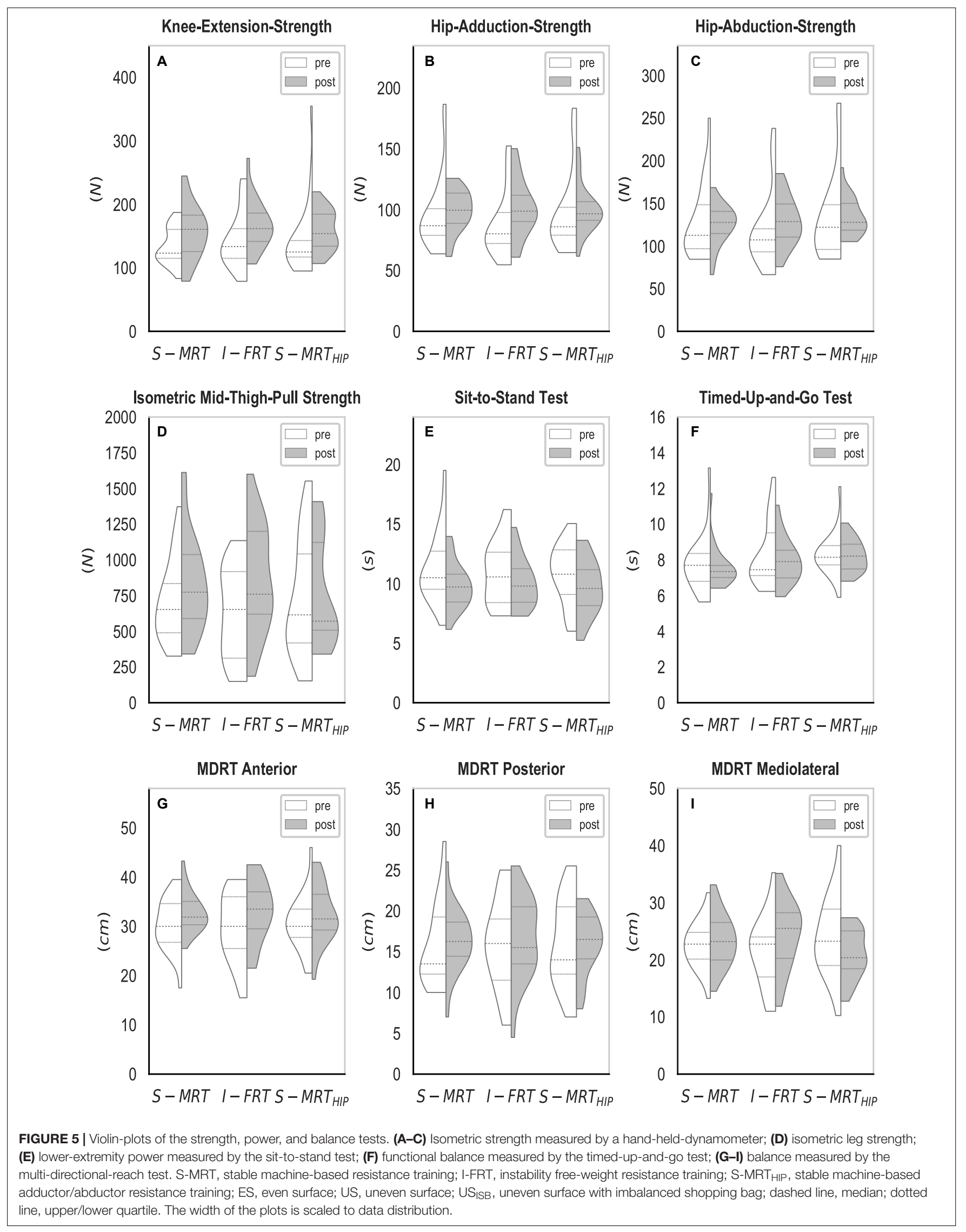


TABLE 4 | ANOVA outcomes.

\begin{tabular}{|c|c|c|c|c|c|c|c|c|c|}
\hline & \multicolumn{3}{|c|}{$\begin{array}{l}\text { Main effect } \\
\text { time }\end{array}$} & \multicolumn{3}{|c|}{$\begin{array}{l}\text { Main effect } \\
\text { group }\end{array}$} & \multicolumn{3}{|c|}{$\begin{array}{l}\text { Interaction } \\
\text { time x group }\end{array}$} \\
\hline & $\boldsymbol{F}$ & $p$ & $d$ & $\boldsymbol{F}$ & $p$ & $D$ & $\boldsymbol{F}$ & $p$ & $d$ \\
\hline \multicolumn{10}{|l|}{ UCM ES } \\
\hline$\Delta \mathrm{V}_{\mathrm{Z}}$ & 0.03 & 0.870 & 0.04 & 0.77 & 0.466 & 0.31 & 0.56 & 0.573 & 0.26 \\
\hline$V_{U C M}$ & 0.01 & 0.936 & 0.02 & 1.01 & 0.370 & 0.35 & 0.76 & 0.474 & 0.31 \\
\hline $\mathrm{V}_{\mathrm{ORT}}$ & 0.01 & 0.999 & $<0.01$ & 0.17 & 0.842 & 0.14 & 0.12 & 0.887 & 0.13 \\
\hline $\mathrm{V}_{\text {TOT }}$ & 0.01 & 0.986 & $<0.01$ & 0.99 & 0.377 & 0.35 & 0.68 & 0.510 & 0.29 \\
\hline \multicolumn{10}{|l|}{ UCM US } \\
\hline$\Delta \mathrm{V}_{\mathrm{Z}}$ & 2.33 & 0.132 & 0.38 & 0.07 & 0.929 & 0.09 & 4.11 & 0.021 & 0.71 \\
\hline$V_{U C M}$ & 25.21 & $<0.001$ & 1.24 & 1.62 & 0.205 & 0.45 & 0.98 & 0.381 & 0.35 \\
\hline$V_{\text {ORT }}$ & 2.08 & 0.154 & 0.36 & 0.31 & 0.732 & 0.20 & 7.02 & 0.002 & 0.93 \\
\hline V $_{\text {TOT }}$ & 26.76 & $<0.001$ & 1.28 & 1.23 & 0.299 & 0.39 & 1.75 & 0.182 & 0.46 \\
\hline \multicolumn{10}{|l|}{ UCM US ISB } \\
\hline$\Delta \mathrm{V}_{\mathrm{Z}}$ & 3.52 & 0.065 & 0.46 & 1.17 & 0.318 & 0.38 & 6.53 & 0.003 & 0.88 \\
\hline$V_{\text {UCM }}$ & 20.16 & $<0.001$ & 1.23 & 2.23 & 0.116 & 0.52 & 0.69 & 0.505 & 0.29 \\
\hline $\mathrm{V}_{\mathrm{ORT}}$ & 2.52 & 0.117 & 0.39 & 0.33 & 0.722 & 0.20 & 7.04 & 0.002 & 0.93 \\
\hline $\mathrm{V}_{\text {TOT }}$ & 22.17 & $<0.001$ & 1.17 & 1.61 & 0.208 & 0.44 & 1.36 & 0.265 & 0.41 \\
\hline \multicolumn{10}{|l|}{ Balance } \\
\hline TUG & 3.04 & 0.087 & 0.43 & 1.44 & 0.245 & 0.42 & 0.53 & 0.589 & 0.26 \\
\hline MDRT forward & 14.33 & $<0.001$ & 0.94 & 0.29 & 0.748 & 0.19 & 0.29 & 0.748 & 0.19 \\
\hline MDRT backward & 0.69 & 0.411 & 0.20 & 0.05 & 0.953 & 0.06 & 0.11 & 0.896 & 0.11 \\
\hline MDRT ML & 0.22 & 0.643 & 0.11 & 0.09 & 0.911 & 0.11 & 5.88 & 0.004 & 0.85 \\
\hline \multicolumn{10}{|l|}{$\begin{array}{l}\text { Strength and } \\
\text { power }\end{array}$} \\
\hline STS & 26.34 & $<0.001$ & 1.27 & 0.14 & 0.874 & 0.13 & 0.68 & 0.509 & 0.29 \\
\hline IMTP & 58.64 & $<0.001$ & 1.90 & 0.03 & 0.973 & 0.06 & 11.98 & 0.001 & 1.21 \\
\hline Hip adduction & 2.57 & 0.117 & 0.39 & 0.29 & 0.752 & 0.19 & 0.91 & 0.407 & 0.33 \\
\hline Hip abduction & 0.31 & 0.580 & 0.14 & 0.57 & 0.570 & 0.26 & 0.40 & 0.670 & 0.22 \\
\hline Knee extension & 11.37 & $<0.001$ & 0.84 & 0.63 & 0.535 & 0.28 & 0.16 & 0.852 & 0.14 \\
\hline \multicolumn{10}{|l|}{ Questionaire } \\
\hline FES-I & 12.36 & $<0.001$ & 0.87 & 0.41 & 0.669 & 0.22 & 0.84 & 0.436 & 0.32 \\
\hline \multicolumn{10}{|l|}{ Gait speed } \\
\hline ES & 12.61 & $<0.001$ & 0.89 & 4.61 & 0.013 & 0.76 & 0.32 & 0.730 & 0.20 \\
\hline US & 10.13 & 0.001 & 0.80 & 2.03 & 0.014 & 0.51 & 0.50 & 0.608 & 0.25 \\
\hline$U_{S_{I S B}}$ & 4.97 & 0.029 & 0.56 & 1.14 & 0.327 & 0.38 & 0.30 & 0.744 & 0.19 \\
\hline \multicolumn{10}{|c|}{ 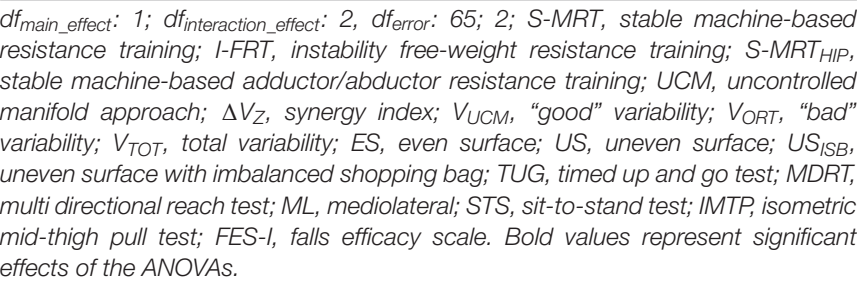 } \\
\hline
\end{tabular}

group only was also supported. We found decisive evidence for an increased magnitude of the synergy index in the US and in the US ISB condition. Consistent with our third hypothesis these stronger synergies were due to reduced "bad" variance for I-FRT while walking across the more challenging conditions; i.e., US and $\mathrm{US}_{\text {ISB }}$. All groups were able to rely on motor flexibility (proportional increase of "good" variability in relation to "bad" variability) to maintain a kinematic synergy at posttesting and across conditions. To the best of our knowledge, this is the first study investigating the use of the UCM approach to quantify (instability) resistance training induced changes within multi-segmental lower-extremity kinematic synergies to stabilize an important performance variable (i.e., ML swing-foot trajectory).
TABLE 5 | T-test pre-post comparisons.

\begin{tabular}{|c|c|c|c|c|c|c|}
\hline & & $t$ & $p$ & $d_{\text {unb }}$ & $95 \mathrm{Cl} d_{\mathrm{unb}}$ & $B F$ \\
\hline \multicolumn{7}{|l|}{ UCM US } \\
\hline \multirow[t]{3}{*}{$\Delta V_{Z}$} & S-MRT & -0.36 & 0.999 & -0.08 & $-0.54,0.38$ & 0.23 \\
\hline & I-FRT & 4.68 & $<0.001$ & 0.96 & $0.47,1.51$ & 200.58 \\
\hline & S-MRT $T_{H I P}$ & -0.21 & 0.999 & -0.06 & $0.58,0.47$ & 0.22 \\
\hline \multirow[t]{3}{*}{$V_{O R T}$} & S-MRT & 2.61 & 0.036 & 0.55 & $0.11,1.03$ & 3.42 \\
\hline & I-FRT & -2.76 & 0.036 & -0.54 & $-0.98,-0.12$ & 8.50 \\
\hline & S-MRT $T_{\text {HIP }}$ & 2.07 & 0.050 & 0.56 & $-0.01,1.15$ & 1.31 \\
\hline \multicolumn{7}{|c|}{ UCM US ${ }_{I S B}$} \\
\hline \multirow[t]{3}{*}{$\Delta V_{Z}$} & S-MRT & -0.61 & 0.999 & -0.14 & $-0.61,0.32$ & 0.26 \\
\hline & I-FRT & 5.63 & $<0.001$ & 1.15 & $0.63,1.73$ & 1421.66 \\
\hline & S-MRT $T_{H I P}$ & -0.16 & 0.999 & -0.04 & $-0.57,0.48$ & 0.22 \\
\hline \multirow[t]{3}{*}{$V_{\text {ORT }}$} & S-MRT & 2.75 & 0.034 & 0.54 & $0.09,1.01$ & 3.13 \\
\hline & I-FRT & -2.80 & 0.033 & -0.53 & $-0.96,-0.12$ & 9.19 \\
\hline & S-MRT $T_{\text {HIP }}$ & 2.17 & 0.041 & 0.59 & $0.03,1.19$ & 1.54 \\
\hline \multicolumn{7}{|l|}{ Balance } \\
\hline \multirow[t]{3}{*}{ MDRT ML } & S-MRT & 0.86 & 0.398 & 0.21 & $-0.29,0.72$ & 0.48 \\
\hline & I-FRT & 2.78 & 0.036 & 0.45 & $0.10,0.82$ & 8.91 \\
\hline & S-MRT $T_{H I P}$ & -2.08 & 0.098 & -0.49 & $-0.99,0.01$ & 0.08 \\
\hline \multicolumn{7}{|l|}{ Strength } \\
\hline \multirow[t]{3}{*}{ IMTP } & S-MRT & 3.85 & $<0.001$ & 0.33 & $0.14,0.55$ & 83.57 \\
\hline & I-FRT & 9.28 & $<0.001$ & 0.65 & $0.42,0.92$ & $2.31^{e+6}$ \\
\hline & S-MRT $T_{\text {HIP }}$ & 1.16 & 0.259 & -0.09 & $-0.07,0.25$ & 0.68 \\
\hline
\end{tabular}

Load

$\begin{array}{lccccc}\text { S-MRT vs. I-FRT } & 15.24 & <0.001 & 4.34 & 3.34,5.46 & 3.91^{*} 10^{16} \\ \text { S-MRT vs. S-MRT } & 9.19 & <0.001 & 2.64 & 1.88,3.48 & 8.21^{*} 10^{08} \\ \text { I-FRT vs. S-MRT }_{\text {HIP }} & 9.86 & <0.001 & 2.72 & 1.98,3.52 & 3.04 * 10^{10}\end{array}$

S-MRT, stable machine-based resistance training; I-FRT, instability freeweight resistance training; S-MRT HIP, stable machine-based adductorlabductor resistance training; $M$, mean; $S D$, standard deviation; UCM, uncontrolled manifold approach; $\Delta V_{Z}$, synergy index; $V_{O R T}$, "bad" variability; US, uneven surface; US ISB, uneven surface with imbalanced shopping bag; TUG, timed up and go test; MDRT, multi directional reach test; ML, mediolateral; IMTP, isometric mid-thigh pull test. Bold values represent signifcant and meaningful effects of the t-tests.

Previous research using the UCM analysis to investigate practice effects on coordination suggested a two-stage process of adaption in multi-segmental coordination (Wu and Latash, 2014). In the first stage "bad" variability drops due to optimized performance control, while "good" variability hardly changes. The second stage is characterized by a reduction in "good" variability, while "bad" variability remains constant. This can be explained by practice-induced optimized control over elemental features, other than the explicit performance variable ( $\mathrm{Wu}$ and Latash, 2014). However, there are scenarios where a practiceinduced increase of $\mathrm{V}_{\mathrm{UCM}}$ can be found. An increase of $V_{\text {UCM }}$ suggests a more robust and flexible system which can exploit an abundance of motor solutions, especially when being challenged (Wu and Latash, 2014; Latash and Huang, 2015). Our results certainly support the first stage, given the drop of $\mathrm{V}_{\mathrm{ORT}}$ during both US conditions and the accompanying increase in the kinematic synergy. The fact that we observed an increase rather than a drop in $\mathrm{V}_{\mathrm{UCM}}$ during the US conditions may be explained by increased gait speed. Given that gait speed increased following the intervention and that variability increases with speed, particularly at faster-than-preferred speed (Chien et al., 2015), we expected an increase particularly in performance destabilizing "bad" variability (Rosenblatt et al., 2014, 2015; Chien 


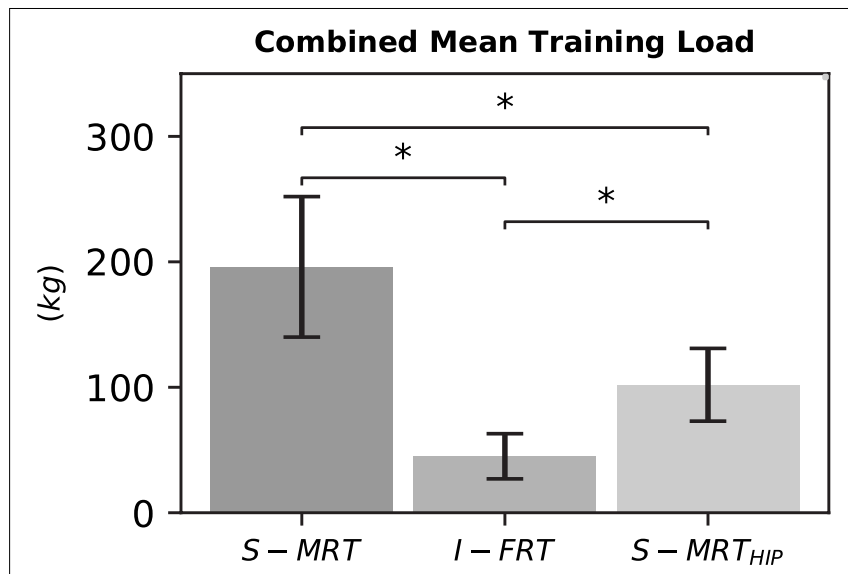

FIGURE 6 | Combined mean load of the two main exercises during the last training phase. S-MRT, stable machine-based resistance training; I-FRT, instability free-weight resistance training; S-MRT $T_{H I P}$, stable machine-based adductor/abductor resistance training. Error bars represent standard deviation. Asterisk "**indicates a significant difference $(p \leq 0.05)$.

et al., 2015). With regard to the specific variance components, increases in movement speed have previously been associated with increased V VRT (Chien et al., 2015; Rosenblatt et al., 2015) which is observed in the two machine-based groups. To counter the increased $\mathrm{V}_{\mathrm{ORT}}$ these groups rely on motor flexibility and increase $\mathrm{V}_{\mathrm{UCM}}$ as well, which is consistent with our previous cross-sectional study in which older adults compensated for challenged stability during walking by increasing $\mathrm{V}_{\mathrm{UCM}}$ (Eckardt and Rosenblatt, 2018). The fact that I-FRT decreased VORT while walking across both US conditions despite increased gait speed is therefore noteworthy and consistent with the second stage of motor learning (Wu and Latash, 2014). The concurrent increase in $\mathrm{V}_{\mathrm{UCM}}$ for this group highlights the fact that I-FRT specifically improved coordination, not to compensate for an increase in $\mathrm{V}_{\text {ORT }}$ but as means to develop coordination among elements to allow flexible performance and avoid reliance on a unique solution (Wu and Latash, 2014; Latash and Huang, 2015).

Several prior studies support the idea that resistance training incorporating modalities that promote exploration of movement space may positively affect motor flexibility. For example, Hamed et al. (2018) showed that while both I-FRT (or exercise dynamic stability under unstable conditions as they call it) and S-MRT improved muscle strength and balance recovery in simulated forward falls, only I-FRT increased standing balance abilities. The authors attributed the effects of I-FRT on the fact that the RT is performed under continuously destabilizing conditions that require continuous processing and integration of sensory afferent information to attain an appropriate motor response (Hamed et al., 2018), which is critical to control of dynamic postural stability under the unstable conditions. Exercising under unpredictable/instable conditions requires motor output to remain flexible enough to produce appropriate responses to continuously changing input. Indeed, recent investigations on adaptive mechanisms during uneven surface walking and running shows a widening of neuromuscular synergies (EMG) to provide robust and flexible motor solutions to compensate for perturbations (Santuz et al., 2018). Interventions forcing the CNS to explore an abundant number of motor solutions can elicit robust and more flexible neuromuscular synergies (EMG) (Oliveira et al., 2017).

In addition to increasing kinematic synergies, we found that I-FRT resulted in an increase in leg extension strength, which is in contrast to a previous RCT by our group (Eckardt, 2016). Indeed, the improvements for I-FRT in this study are larger than the prior RCT (Cohen's $d$ : 0.50 vs. 0.65 ). A different protocol to estimate training load may explain this difference. In our prior study, the 1-RM was calculated on the respective instability device whereas the current study calculated the training load on even surface. However, it may be difficult to elicit a true 1-RM on instability devices. In fact, the 1-RM for I-FRT was slightly higher in this study compared to the prior one $(8 \pm 4 \mathrm{~kg})$ which may elicit the present effect and the subsequent interaction effect time $x$ group.

It was somewhat unexpected that S-MRT $\mathrm{HIP}_{\mathrm{H}}$ did not improve adductor/abductor strength, which would be predicted based on principles of specificity (Buckthorpe et al., 2015; Contreras et al., 2016). We assume that the hand-held dynamometry test hip strength did not isolate hip adductors/abductors such that the other groups (i.e., S-MRT and I-FRT) could have attained similar testing values by compensating for weaker adductor/abductors with activation of other muscles to coordinate hip movement. Regardless of the reason, the fact that hip adductor/abductor strength did not improve with S-MRT $\mathrm{HIP}_{\mathrm{P}}$, or any of the other modalities, but that changes in the kinematic synergy were seen in I-FRT suggests that the neuromuscular strategies contributing to mediolateral foot placement and in turn synergistic behavior of lower-extremities may depend more on sensorimotor integration during dynamic (i.e., instable) situations than on force producing capabilities of the hip. Indeed both, S-MRT and S-MRTHIP are quite stationary modalities, at least with regarding to the resistance components which were the primary training components; during resistive exercise execution there is little or no unpredicted movement and minimal counter-rotation of segments relative to the CoM (Hamed et al., 2018). Future work should consider individual effects - e.g., are kinematic synergies different between responders (those who increase adductor/adductor strength) and non-responders or do kinematic synergies scale with strength - to better understand the relationship between hip strength and kinematic synergies during gait.

\section{LIMITATIONS}

Because our participants were healthy older adults (mean TUG time at pre-testing: $8.1 \mathrm{~s}$ ), generalizability to frail older people needs to be established. In addition, the extent to which I-FRT can strengthen synergies (kinematic or otherwise) related to other performance variables has yet to be determined.

Given that the I-FRT group practiced walking across the US, it is not possible to entirely disentangle the impact of repeated US walking from instability RT on kinematic synergies. 
However, given that S-MRT practiced walking with weights and S-MRT $\mathrm{TIP}_{\mathrm{P}}$ practiced resisted walking yet demonstrated an increase rather than a reduction in $\mathrm{V}_{\mathrm{ORT}}$, it appears that $\mathrm{RT}$ training alone, in absence of instability, cannot explain the changes observed in the I-FRT group. In addition, the fact that we observed similar strength changes but differences in motor flexibility between I-FRT and S-MRT suggests that the context in which strength changes occur is critical to promoting motor flexibility.

The high inter-subject variability (see Figures 4, 5) may indicate that there are individual strategies to stabilize the kinematic synergy. Future research should try to identify such subject specific strategies.

\section{CONCLUSION}

The purpose of this RCT was to quantify how different resistance training modalities affect kinematic synergies related to the mediolateral trajectory of the swing-foot during normal and perturbed gait. For all groups the kinematic synergy during normal gait (ES condition) was unaffected by RT. However, I-FRT demonstrated significant increases in the kinematic synergy on the uneven surface which was achieved by reducing motor noise $\left(\mathrm{V}_{\mathrm{ORT}}\right)$ and therefore stabilizing the ML trajectory of the swing foot. To our knowledge, this is the first time the UCM approach was used to quantify resistance training induced effects on locomotor stability.

\section{DATA AVAILABILITY}

All datasets analyzed for this study are included in the Supplementary Material SI.

\section{REFERENCES}

Arnold, C. M., Warkentin, K. D., Chilibeck, P. D., and Magnus, C. R. A. (2010). The reliability and validity of handheld dynamometry for the measurement of lower-extremity muscle strength in older adults. J. Strength Cond. Res. 24, 815-824. doi: 10.1519/JSC.0b013e3181aa36b8

Benichou, O., and Lord, S. R. (2016). Rationale for strengthening muscle to prevent falls and fractures: a review of the evidence. Calcif. Tissue Int. 98, 531-545. doi: 10.1007/s00223-016-0107-9

Benke, T., Karner, E., and Delazer, M. (2013). FAB-D: german version of the frontal assessment battery. J. Neurol. 260, 2066-2072. doi: 10.1007/s00415-013-6929-8

Berg, W. P., Alessio, H. M., Mills, E. M., and Tong, C. (1997). Circumstances and consequences of falls in independent community-dwelling older adults. Age Ageing 26, 261-268. doi: 10.1093/ageing/26.4.261

Brach, J. S., Berlin, J. E., VanSwearingen, J. M., Newman, A. B., and Studenski, S. A. (2005). Too much or too little step width variability is associated with a fall history in older persons who walk at or near normal gait speed. J. Neuroeng. Rehabil. 2:21.

Bruijn, S. M., and van Dieën, J. H. (2018). Control of human gait stability through foot placement. J. R. Soc. Interface 15:20170816. doi: 10.1098/rsif.2017.0816

Buckthorpe, M., Erskine, R. M., Fletcher, G., and Folland, J. P. (2015). Task-specific neural adaptations to isoinertial resistance training. Scand. J. Med. Sci. Sport 25, 640-649. doi: 10.1111/sms.12292

Chien, J. H., Yentes, J., Stergiou, N., and Siu, K.-C. (2015). The Effect of Walking Speed on Gait Variability in Healthy Young, Middle-Aged and Elderly

\section{AUTHOR CONTRIBUTIONS}

$\mathrm{NE}$ analyzed the data, wrote the manuscript, and contributed to the conception and design of the study. NR contributed to the study design, assisted with the data analysis and interpretation, and critical review of the manuscripts. Both authors read and approved the final version of the manuscript.

\section{FUNDING}

The trial was supported by a grant of the Regional Government of Hessen (Germany) and task (Center for Transfer and Application in Sports Kassel).

\section{ACKNOWLEDGMENTS}

We thank Meagen L., Kai V., Ingo K., and Elisabeth H. for the data acquisition and Jonas L., Yanneck N., Simon D., and Heiko W. for carrying out the training programs. Further, we would like to thank sensa ${ }^{\circledR}$ by Huebner Group for providing terrasensa plates and $\mathrm{h} / \mathrm{p} /$ cosmos for providing the treadmill. In addition, we thank Daniel W., and Daniel K. for their help with the R-code.

\section{SUPPLEMENTARY MATERIAL}

The Supplementary Material for this article can be found online at: https://www.frontiersin.org/articles/10.3389/fnagi. 2019.00032/full\#supplementary-material

MATERIAL SI | Dataset.

MATERIAL SII | Detailed UCM approach.

Individuals. Available at: http://www.panr.com.cy/index.php/article/the-effectof-walking-speed-on-gait-variability-in-healthy-young-middle-aged-andelderly-individuals/

Cohen, J. (1988). Statistical Power Analysis for the Behavioral Sciences. Hillsdale, N.J: L. Erlbaum Associates.

Contreras, B., Vigotsky, A. D., Schoenfeld, B. J., Beardsley, C., McMaster, D. T., Reyneke, J., et al. (2016). Effects of a six-week hip thrust versus front squat resistance training program on performance in adolescent males: a randomized-controlled trial. J. Strength Cond. Res. 31, 999-1008. doi: 10.1519/ JSC.0000000000001510

Cumming, G. (2012). Understanding the New Statistics: Effect Sizes, Confidence Intervals, and Meta-Analysis. New York, NY: Routledge.

Dias, N., Kempen, G. I. J. M., Todd, C. J., Beyer, N., Freiberger, E., Piot-Ziegler, C., et al. (2006). Die deutsche version der falls efficacy scale-international version (FES-I). Z. Gerontol. Geriatr. 39, 297-300. doi: 10.1007/s00391-006-0400-8

Dubois, B., Slachevsky, A., Litvan, I., and Pillon, B. (2000). The FAB: a frontal assessment battery at bedside. Neurology 55, 1621-1626. doi: 10.1212/WNL.57. 3.565

Eckardt, N. (2016). Lower-extremity resistance training on unstable surfaces improves proxies of muscle strength, power and balance in healthy older adults: a randomised control trial. BMC Geriatr. 16:191. doi: 10.1186/s12877-0160366-3

Eckardt, N., and Rosenblatt, N. J. (2018). Healthy aging does not impair lower extremity motor flexibility while walking across an uneven surface. Hum. Mov. Sci. 62, 67-80. doi: 10.1016/J.HUMOV.2018.09.008 
Frey, I., and Berg, A. (2002). Physical activity counseling: assessment of physical activity by questionnaire. Eur. J. Sport Sci. 2, 1-6. doi: 10.1080/ 17461390200072406

Greve, C., Zijlstra, W., Hortobágyi, T., and Bongers, R. M. (2013). Not all is lost: old adults retain flexibility in motor behaviour during sit-to-stand. PLoS One 8:e77760. doi: 10.1371/journal.pone.0077760

Hamed, A., Bohm, S., Mersmann, F., and Arampatzis, A. (2018). Exercises of dynamic stability under unstable conditions increase muscle strength and balance ability in the elderly. Scand. J. Med. Sci. Sport 28, 961-971. doi: 10.1111/ sms.13019

Kang, H. G., and Dingwell, J. B. (2009). Dynamics and stability of muscle activations during walking in healthy young and older adults. J. Biomech. 42, 2231-2237. doi: 10.1016/j.jbiomech.2009.06.038

Kapur, S., Zatsiorsky, V. M., and Latash, M. L. (2010). Age-related changes in the control of finger force vectors. J. Appl. Physiol. 109, 1827-1841. doi: 10.1152/ japplphysiol.00430.2010

Krishnan, V., Rosenblatt, N. J., Latash, M. L., and Grabiner, M. D. (2013). The effects of age on stabilization of the mediolateral trajectory of the swing foot. Gait Posture 38, 923-928. doi: 10.1016/j.gaitpost.2013.04.023

Kuo, A. D. (2002). The relative roles of feedforward and feedback in the control of rhythmic movements. Motor Control 6, 129-145. doi: 10.1123/mcj.6.2.129

Latash, M. L., and Huang, X. (2015). Neural control of movement stability: lessons from studies of neurological patients. Neuroscience 301, 39-48. doi: 10.1016/j. neuroscience.2015.05.075

Latash, M. L., Scholz, J. P., and Schöner, G. (2007). Toward a new theory of motor synergies. Motor Control 11, 276-308. doi: 10.1123/mcj.11.3.276

Lawrence, M. A., and Carlson, L. A. (2015). Effects of an unstable load on force and muscle activation during a parallel back squat. J. Strength Cond. Res. Strength Cond. Assoc. 29, 2949-2953. doi: 10.1519/JSC.0000000000000955

Leardini, A., Sawacha, Z., Paolini, G., Ingrosso, S., Nativo, R., and Benedetti, M. G. (2007). A new anatomically based protocol for gait analysis in children. Gait Posture 26, 560-571. doi: 10.1016/j.gaitpost.2006.12.018

Lopez, M. N., Charter, R. A., Mostafavi, B., Nibut, L. P., and Smith, W. E. (2005). Psychometric properties of the folstein mini-mental state examination. Assessment 12, 137-144. doi: 10.1177/1073191105275412

McMaster, D. T., Gill, N., Cronin, J., and McGuigan, M. (2014). A brief review of strength and ballistic assessment methodologies in sport. Sport Med. 44, 603-623. doi: 10.1007/s40279-014-0145-2

Moeskops, S., Oliver, J. L., Read, P. J., Cronin, J. B., Myer, G. D., Haff, G. G., et al. (2018). Within- and between-session reliability of the isometric mid-thigh pull in young female athletes. J. Strength Cond. Res. 32:1. doi: 10.1519/JSC. 0000000000002566

Nair, A. K., Gavett, B. E., Damman, M., Dekker, W., Green, R. C., Mandel, A., et al. (2010). Clock drawing test ratings by dementia specialists: interrater reliability and diagnostic accuracy. J. Neuropsychiatry Clin. Neurosci. 22, 85-92. doi: 10.1176/appi.neuropsych.22.1.85

Newton, R. A. (2001). Validity of the multi-directional reach test: a practical measure for limits of stability in older adults. J. Gerontol. A Biol. Sci. Med. Sci. 56, M248-M252. doi: 10.1093/gerona/56.4.M248

Oliveira, A. S., Silva, P. B., Lund, M. E., Farina, D., and Kersting, U. G. (2017). Balance training enhances motor coordination during a perturbed side-step cutting task. J. Orthop. Sport Phys. Ther. 47, 1-32. doi: 10.2519/jospt.2017.6980

Parmelee, P. A., and Katz, I. R. (1990). Geriatric depression scale. J. Am. Geriatr. Soc. 38:1379. doi: 10.1111/j.1532-5415.1990.tb03461.x

Podsiadlo, D., and Richardson, S. (1991). The timed "Up \& Go": a test of basic functional mobility for frail elderly persons. J. Am. Geriatr. Soc. 39, 142-148. doi: 10.1111/j.1532-5415.1991.tb01616.x
Pohl, M. B., Kendall, K. D., Patel, C., Wiley, J. P., Emery, C., and Ferber, R. (2015). Experimentally reduced hip-abductor muscle strength and frontalplane biomechanics during walking. J. Athl. Train. 50, 385-391. doi: 10.4085/ 1062-6050-49.5.07

Rankin, B. L., Buffo, S. K., and Dean, J. C. (2014). A neuromechanical strategy for mediolateral foot placement in walking humans. J. Neurophysiol. 112, 374-383. doi: 10.1152/jn.00138.2014

Reynolds, J. M., Gordon, T. J., and Robergs, R. A. (2006). Prediction of one repetition maximum strength from multiple repetition maximum testing and anthropometry. J. Strength Cond. Res. 20:584. doi: 10.1519/R-15304.1

Roden-Reynolds, D. C., Walker, M. H., Wasserman, C. R., and Dean, J. C. (2015). Hip proprioceptive feedback influences the control of mediolateral stability during human walking. J. Neurophysiol. 114, 2220-2229. doi: 10.1152/jn.00551. 2015

Rosenblatt, N. J., Hurt, C. P., Latash, M. L., and Grabiner, M. D. (2014). An apparent contradiction: increasing variability to achieve greater precision? Exp. Brain Res. 232, 403-413. doi: 10.1007/s00221-013-3748-1

Rosenblatt, N. J., Latash, M. L., Hurt, C. P., and Grabiner, M. D. (2015). Challenging gait leads to stronger lower-limb kinematic synergies: the effects of walking within a more narrow pathway. Neurosci. Lett. 600, 110-114. doi: 10.1016/j. neulet.2015.05.039

Rubenstein, L. Z. (2006). Falls in older people: epidemiology, risk factors and strategies for prevention. Age Ageing 35, ii37-ii41. doi: 10.1093/ageing/afl084

Santuz, A., Ekizos, A., Eckardt, N., Kibele, A., and Arampatzis, A. (2018). Challenging human locomotion: stability and modular organisation in unsteady conditions. Sci. Rep. 8:2740. doi: 10.1038/s41598-018-21018-4

Schmider, E., Ziegler, M., Danay, E., Beyer, L., and Bühner, M. (2010). Is it really robust?: reinvestigating the robustness of ANOVA against violations of the normal distribution assumption. Methodology 6, 147-151. doi: 10.1027/16142241/a000016

Scholz, J. P., and Schöner, G. (1999). The uncontrolled manifold concept: identifying control variables for a functional task. Exp. Brain Res. 126, 289-306. doi: $10.1007 / \mathrm{s} 002210050738$

Shim, J. K., Hsu, J., Karol, S., and Hurley, B. F. (2008). Strength training increases training-specific multifinger coordination in humans. Motor Control 12, 311329. doi: $10.1123 / \mathrm{mcj} .12 .4 .311$

Tiedemann, A., Shimada, H., Sherrington, C., Murray, S., and Lord, S. (2008). The comparative ability of eight functional mobility tests for predicting falls in community-dwelling older people. Age Ageing 37, 430-435. doi: 10.1093/ ageing/afn 100

Wetzels, R., Matzke, D., Lee, M. D., Rouder, J. N., Iverson, G. J., and Wagenmakers, E. J. (2011). Statistical evidence in experimental psychology: an empirical comparison using $855 \mathrm{t}$ tests. Perspect. Psychol. Sci. 6, 291-298. doi: 10.1177/ 1745691611406923

Wu, Y. H., and Latash, M. L. (2014). The effects of practice on coordination. Exerc. Sport Sci. Rev. 42, 37-42. doi: 10.1249/JES.0000000000000002

Conflict of Interest Statement: The authors declare that the research was conducted in the absence of any commercial or financial relationships that could be construed as a potential conflict of interest.

Copyright $\odot 2019$ Eckardt and Rosenblatt. This is an open-access article distributed under the terms of the Creative Commons Attribution License (CC BY). The use, distribution or reproduction in other forums is permitted, provided the original author(s) and the copyright owner(s) are credited and that the original publication in this journal is cited, in accordance with accepted academic practice. No use, distribution or reproduction is permitted which does not comply with these terms. 